\title{
EL INCREMENTO DE LA POBLACIÓN EXTRANJERA EN LA PROVINCIA DE ALICANTE. LOS CONTRASTES EN SU DISTRIBUCIÓN ESPACIAL ${ }^{1}$
}

\author{
Ernesto Cutillas Orgilés \\ Departamento de Geografía Humana \\ Universidad de Alicante
}

\section{RESUMEN}

Alicante es la provincia española que en 2005 tiene mayor proporción de población extranjera. Previo al análisis de la evolución y la distribución más reciente de esta población, hay que considerar las distintas motivaciones de los extranjeros que eligen la provincia de Alicante, ya sea para residir, como es el caso de muchos ciudadanos de la Europa económicamente más desarrollada; o para trabajar, como sucede, principalmente con los colectivos de extranjeros que acuden desde Latinoamérica, África o Europa Oriental. Frente a un litoral que concentra la mayor cantidad de extranjeros, especialmente turistas residenciales, queda el interior provincial con el menor número de extranjeros. Como ejemplo especial, se estudia la distribución de la población extranjera en la conurbación Elda-Petrer, al ser éste el núcleo urbano más poblado del interior provincial, y que, aparentemente, tiene una dinámica migratoria distinta a los municipios del litoral alicantino.

Palabras clave: extranjeros, provincia de Alicante, turista residencial, inmigrantes laborales, Elda-Petrer.

\begin{abstract}
Of all the Spanish provinces, Alicante had the highest foreign population in 2005. Before analysing the most recent evolution and distribution of this population, it is necessary to consider the different reasons why foreigners choose the province of Alicante, whether it be to live, as is the case for many citizens of the more developed parts of Europe, or to work, as is often the case when groups arrive from Latin America, Africa or Eastern Europe. Compared with the coastal areas where most foreigners, particularly residential tourists,
\end{abstract}

1 Esta investigación se ha desarrollado dentro del Proyecto «La inmigración femenina (africana y latinoamericana) en la España mediterránea», Ref. BSO2002-00229, financiado por el Ministerio de Ciencia y Tecnología, Secretaría de Estado de Política Científica y Tecnológica. Dirección General de Investigación. 
decide to settle, the interior of the province has a low foreign population density. As a case study, we have analysed the distribution of the foreign population in the Elda-Petrer conurbation, as this is the province's most populated inland urban nucleus and seems to have different migratory characteristics to those of Alicante's coastal towns.

Key words: foreigners, province of Alicante, residential tourist, working immigrants, Elda-Petrer.

\section{Introducción}

Durante los años 1990 el número de extranjeros residentes en la provincia de Alicante ha aumentado significativamente, en especial a partir del final de la década y a comienzos del siglo XXI. En ese sentido, el actual ritmo de crecimiento de la población en nuestro ámbito de estudio no depende sólo de la natalidad y mortalidad, sino, sobre todo, de los movimientos migratorios. Actualmente las migraciones pueden abordarse desde varias perspectivas, más aún teniendo en cuenta el carácter global de las mismas. Hay muchos factores que inciden en las migraciones, ya sean voluntarias o forzosas, al igual que también afectan la temporalidad o duración de permanencia en el lugar de destino. No obstante, un hecho indiscutible de las migraciones, independientemente de las motivaciones del migrante, supone que hay regiones que pierden población y otras que la ganan, de modo que el territorio, de una u otra forma, va a reflejar esos procesos demográficos.

Existe multitud de clasificaciones para el estudio de las migraciones. Así mismo hay que tener en cuenta el Ciclo Vital en las migraciones, en el que se relacionan los movimientos migratorios y las edades del migrante, pues existe un periodo en la vida de las personas en el que hay más posibilidades de migrar ${ }^{2}$. A ese respecto pueden identificarse dos tipos de movimientos migratorios de la población extranjera que en los últimos años han estado presentes en la provincia de Alicante: 1) los movimientos de población cuyos protagonistas son ciudadanos de Europa Occidental: entre sus características, hay que destacar la adquisición de una vivienda por parte de una población eminentemente envejecida que reside de modo estable en municipios situados preferentemente en la franja litoral de la provincia. 2) los movimientos de población de países menos desarrollados. Este hecho es de aparición muy reciente y tiene una gran trascendencia para toda la sociedad en su conjunto, ya que nos encontramos ante una población no española (ni de la Unión Europea) con circunstancias económicas, sociales y culturales que no siempre suelen ser asumidas con facilidad por la sociedad receptora. Son inmigrantes que, como a lo largo de la historia, se han visto atraídos ante la posibilidad de trabajo y de mejora de su situación económica y familiar. Esta perspectiva no debemos dejarla de lado, debido a su enorme trascendencia en el tejido social del país, más aún cuando estamos ante una población autóctona tendente al envejecimiento acusado, frente a un colectivo inmigrante joven y que tradicionalmente ha desempeñado las ocupaciones desestimadas por los españoles.

2 El Ciclo Vital de las migraciones fue adaptado en 1969 por D. Bouge, en su obra Principles of Demography (citado en d'Entremont, A., 1997). Está pensado para una sociedad madura occidental que se encuentra en el momento final de su transición demográfica, en donde se observa un aumento de la movilidad de la población en función de su edad, ya sea una movilidad residencial o laboral, sin importar el lugar de procedencia de los migrantes. 


\section{Caracterización y distribución de la población extranjera en España}

La distribución de la población extranjera en España a nivel provincial se reparte de manera desigual: Madrid, las Islas Canarias y las provincias ribereñas del Mar Mediterráneo, presentan las mayores concentraciones de extranjeros. Según en Padrón Municipal de Habitantes a 1-01-2005, la provincia de Alicante con el 18,6\% (321.640) de extranjeros sobre el total de su población, es la que alcanza la proporción más alta de foráneos. En ese sentido encontramos 15 provincias con proporciones de extranjeros superiores a la media nacional, 8,5\% (3.730.610) (mapa 1). Por sus cifras absolutas destacan Madrid con 780.752, Barcelona con 569.395, Alicante 321.640, Málaga con 181.589 o las islas Baleares con 156.270.

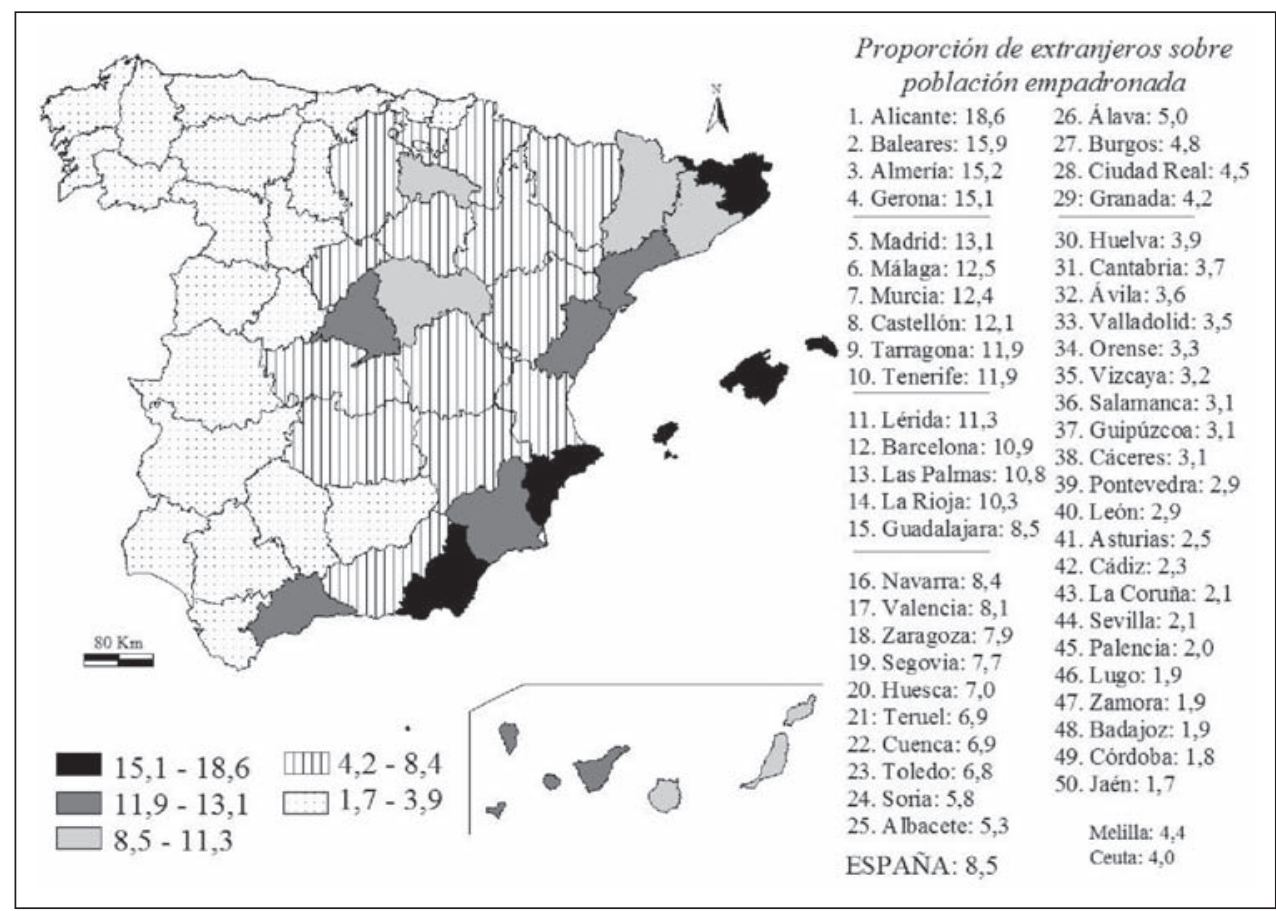

MAPA 1. España 2005, proporción de extranjeros sobre la población total provincial.

Fuente: INE, revisión del Padrón municipal de habitantes, a 1-01-2005. Elaboración propia.

Las provincias españolas con porcentajes más elevados de extranjeros sobre la población total no siempre coinciden con las que cuentan con mayor número (mapa 2). Al igual que el total de extranjeros, las distintas nacionalidades tampoco se reparten de manera homogénea en el país. Las cinco nacionalidades mayoritarias son los marroquíes (511.294), ecuatorianos (497.799), rumanos (317.366), colombianos (271.239) y británicos (227.187). Destacan en primer lugar las provincias de Barcelona y Madrid, por tener la mayor cantidad y diversificación de extranjeros, pero en donde predominan los inmigrados procedentes de países económicamente menos desarrollados que España. En segundo lugar, están provincias donde el turismo desempeña un notable papel en la economía: Alicante, Málaga, Baleares 
o Tenerife, precisamente las provincias en las que puede encontrarse mayor cantidad de ciudadanos británicos, entre otras nacionalidades. Por último, en el resto de provincias el reparto es más heterogéneo, destacando los marroquíes en Almería, Gerona y en menor medida en Murcia, Tarragona y las Palmas; los ecuatorianos en Valencia, Murcia, Alicante y Baleares; los rumanos en Castellón y Zaragoza; y los colombianos en Valencia, Las Palmas y Vizcaya. El resto de provincias españolas, pese a contar también con ciudadanos de éstas y otras nacionalidades, lo hacen con contingentes mucho más reducidos.

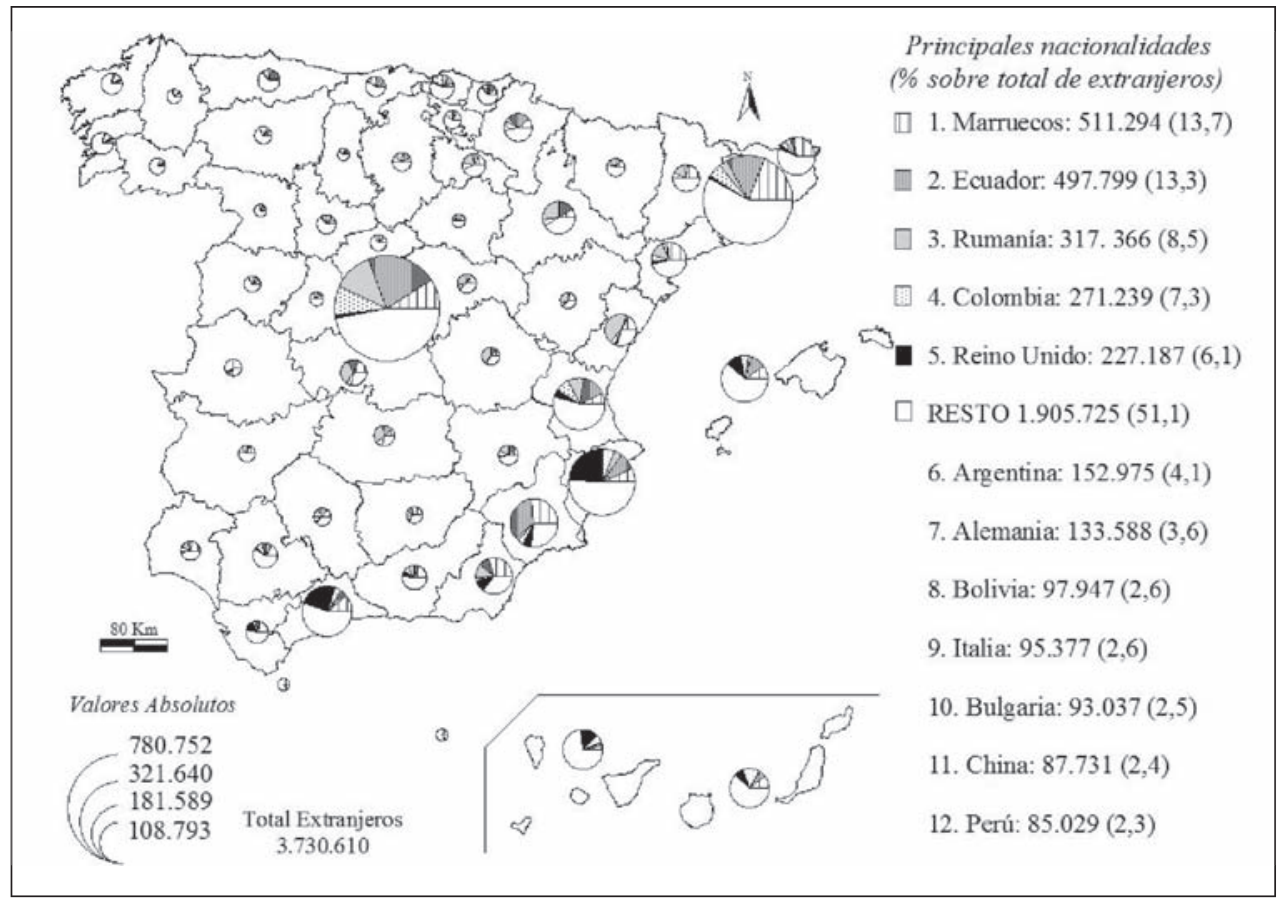

MAPA 2. España 2005, extranjeros según su nacionalidad

Fuente: INE, revisión del Padrón municipal de habitantes, a 1-01-2005. Elaboración propia.

Lo más significativo es la diferencia que hay en la distribución de los extranjeros según sus nacionalidades a) de países europeos occidentales, tanto los que han acudido por motivos residenciales, como por motivos laborales; una buena parte de estos últimos están vinculados con las zonas turísticas donde viven sus compatriotas; y b) de países económicamente menos desarrollados, especialmente de África, Europa del Este y en los últimos años de América Latina. Respecto a estos contingentes de población V. Gozálvez (1992) destaca cuatro hechos clave que subyacen entre estos colectivos de inmigrantes: 1) elevados contingentes de inmigrantes en situación irregular, 2) sucesivos incrementos de extranjeros inducidos por la elevada diferencia de renta de los países emisores respecto a España, 3) fuerte presión demográfica en los países de origen, de lo que se desprende la necesidad de incentivar políticas de desarrollo en esos países, 4) estos inmigrantes desempeñan actividades laborales menos apetecibles para los españoles.

En una primera aproximación a los extranjeros que residen en España, tanto entre los que tienen nacionalidades de países más desarrollados, como entre los extranjeros proce- 
dentes de países económicamente menos desarrollados, hay que tener en cuenta, tal como señalan V. Gozálvez (1989) y J.R. Valero (1992), que las cifras de extranjeros proporcionadas por los censos de población, padrones municipales, subdelegaciones de Gobierno u otras administraciones, no coinciden; por lo que siempre conviene tomar con cautela la información obtenida de los registros oficiales.

\section{La población extranjera en la provincia de Alicante}

Al igual que sucede en el conjunto de España, la provincia de Alicante presenta un reparto geográfico desigual de su población extranjera, puesto que los mayores volúmenes de esta población se localizan en los municipios litorales o prelitorales. En 2005, Torrevieja es el municipio alicantino que tiene el mayor número de extranjeros empadronados: 40.188 (el 47,6\% de su población), seguido por Alicante, 35.588 (11,1\%), Orihuela, $24.324(32,4 \%)$ y Elche $18.666(8,7 \%)$. Esta aproximación a los municipios con mayor número de extranjeros, muestra cómo los municipios de mayor centralidad administrativa y funcional: Alicante y Elche, presentan unos porcentajes reducidos en comparación con los otros municipios, Torrevieja u Orihuela, cuya economía se caracteriza por la enorme importancia que tiene la actividad turística y/o los turistas residenciales. Un ejemplo de lo anteriormente señalado son los municipios que ocupan los siguientes puestos en el ranking de extranjeros: Benidorm 17.115 (25,3\%), Calpe 14.765 (58,6\%), Jávea 14.465 (52,1\%), Denia $11.217(27,8 \%)$ o

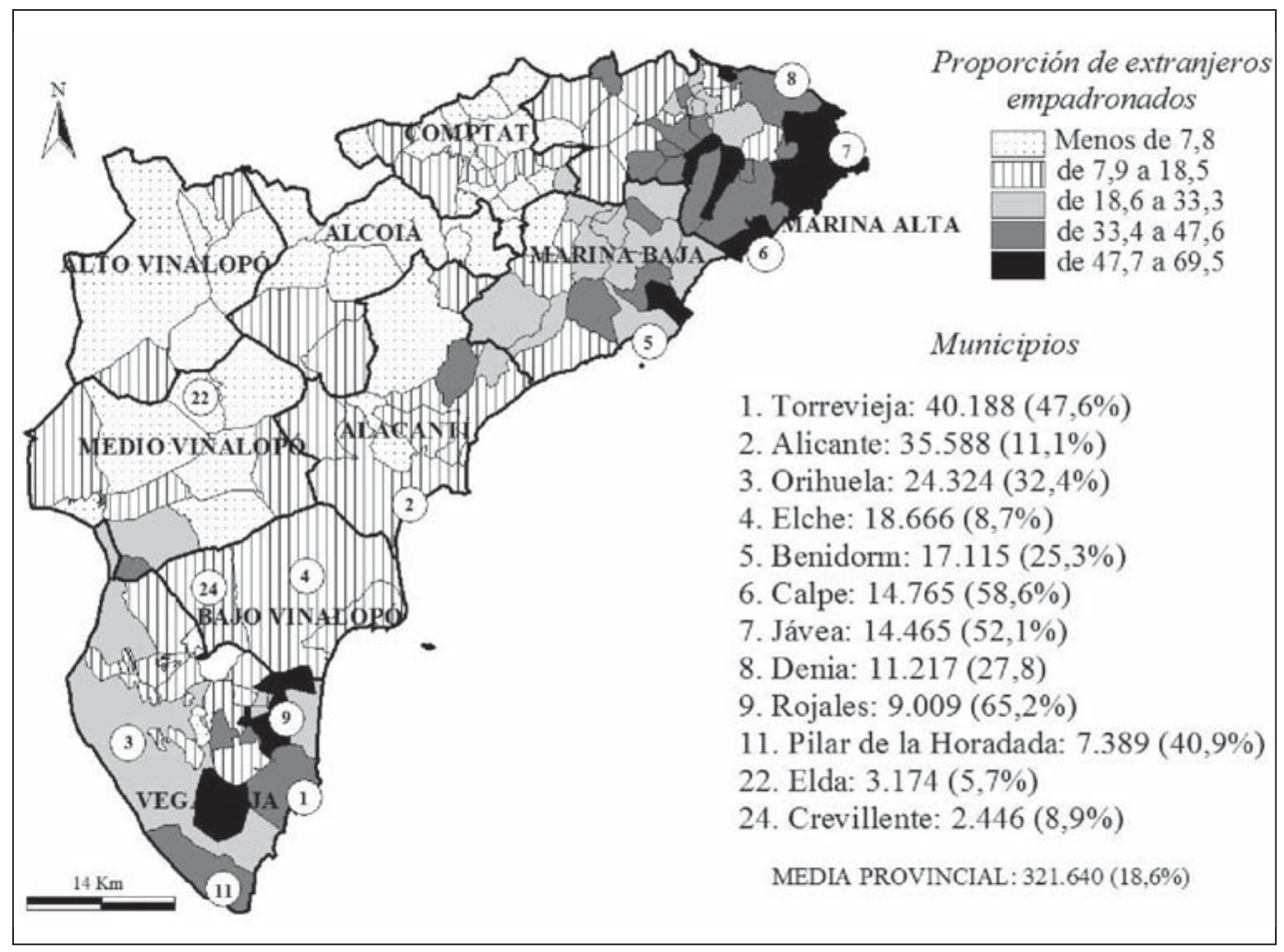

Mapa 3. Alicante 2005, distribución municipal de las proporción de extranjeros sobre la población total

Fuente: INE, revisión del Padrón municipal de habitantes, a 1-01-2005. Elaboración propia. 
Rojales 9.009 (65,2\%), que es el municipio mayor de 10.000 habitantes con la proporción de extranjeros más elevada. El primer municipio del interior en cuanto a número de extranjeros es Elda con 3.174 (5,7\% de su censo demográfico), y ocupa el vigésimo segundo puesto de los municipios alicantinos en número absoluto de extranjeros.

En el litoral provincial los municipios con proporciones de extranjeros más altas se localizan en la Vega Baja, Marina Alta y Marina Baja, donde en ocasiones superan en número a los españoles; por contra, en los municipios del interior, especialmente en las comarcas del Alto Vinalopó, Medio Vinalopó y Alcoià, los extranjeros apenas alcanzan el 7,8\% de la población total en las cabeceras comarcales y en los municipios próximos a éstas.

\subsection{Las principales nacionalidades. Evolución más reciente}

Entre 1998 y 2005 el número de extranjeros residentes censados en la provincia de Alicante ha aumentado en 245.918 personas, al pasar de 75.722 a 321.640 , mientras que la población española en la provincia sólo ha crecido en 97.538 personas. Estos datos muestran cómo la llegada de ciudadanos extranjeros han contribuido decisivamente, a través de saldos migratorios positivos, a incrementar el número de habitantes; las nacionalidades que cuentan con más de 10.000 personas en la provincia son las que siguen: de Europa: Gran Bretaña, Alemania, Rumanía y Holanda; de África, Marruecos, y de Latinoamérica, Ecuador, Colombia y Argentina (cuadro 1).

En 2005, las nacionalidades extranjeras mayoritarias en la provincia de Alicante, a excepción de los alemanes, son prácticamente las mismas, aunque en distinto orden, que en el conjunto nacional: Reino Unido 78.738, Alemania 29.448, Ecuador 26.531, Marruecos 21.548 y Colombia 19.859. No obstante hay que señalar que no siempre han sido estos mismos países los que han tenido el mayor número de ciudadanos durante el periodo de tiempo estudiado. Así por ejemplo, británicos y alemanes eran los únicos extranjeros que en 1998 superaban los 10.000 habitantes, con 23.019 y 13.676 , respectivamente; mientras que holandeses 5.738, marroquíes 2.802 y argentinos 1.390 , tenían una presencia más reducida. En cambio, nacionalidades que en 2005 cuentan con notables contingentes de ciudadanos, tenían en 1998 una presencia testimonial: Rumanía 47, Ecuador 87 y Colombia 299; lo que subraya el carácter muy reciente de la inmigración procedente de esos países.

La población procedente de países económicamente menos desarrollados ha sido la que ha experimentado en la provincia de Alicante los incrementos anuales más acusados. Así, en primer lugar destacan los ciudadanos de Ecuador y de Rumanía, con un crecimiento medio en el periodo $1998-2005$ de $30.395,4 \%$ y $25.885,1 \%$, respectivamente, siendo en ambos casos el año 2001 en el que se registra el incremento anual más sobresaliente: $858,21 \%$ y $555,88 \%$, respectivamente; para luego comenzar un descenso en el ritmo de crecimiento y/o empadronamiento. En segundo lugar se sitúan los ciudadanos colombianos, con un crecimiento medio de $6.541,8 \%$, y los ciudadanos argentinos con el $729,6 \%$, que son, tras el grupo anterior, los extranjeros de los países con más de 10.000 residentes que han incrementado de modo más notable su presencia en la provincia. Los colombianos han tenido un crecimiento porcentual próximo al del grupo anterior, aunque ligeramente más moderado, puesto que su máximo incremento anual, 320,53\%, es en el año 2001; mientras que el caso argentino ${ }^{3}$ es distinto por tratarse de unos ciudadanos que en 1998 ya tenían una

3 Conviene tener presente que si bien los argentinos no constituyen el grupo más numero de extranjeros en la provincia de Alicante, cuentan con más ciudadanos que han nacido en ese país pero que poseen otra nacionalidad, especialmente la española y la italiana. Según el INE, en 2005 hay registradas 17.868 personas en la provincia de Alicante que han nacido en Argentina, pero sólo 11.531 con esa nacionalidad, luego hay 6.337 que tienen otra distinta. 


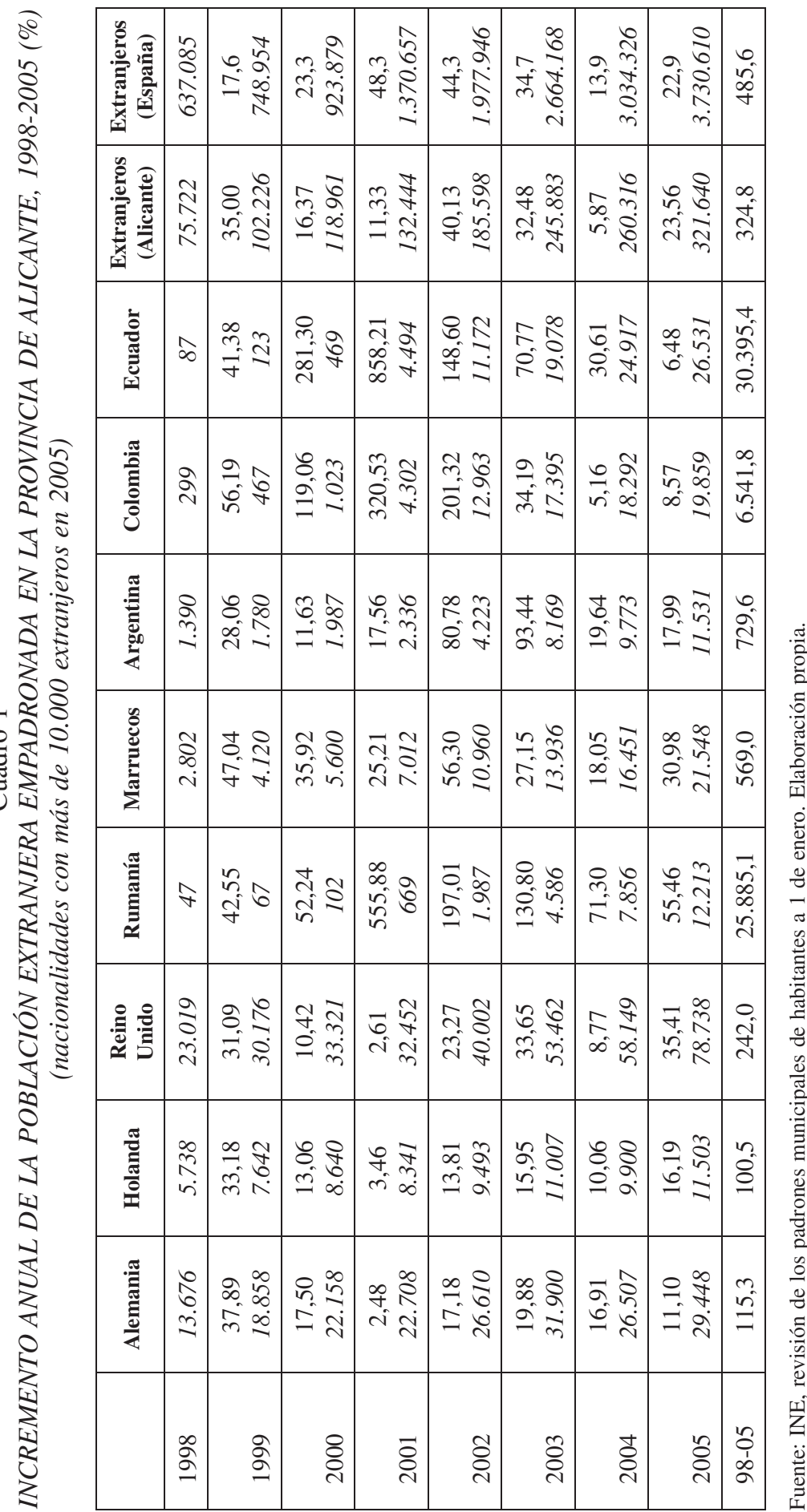


presencia significativa en la provincia, y por registrar los máximos incrementos anuales en los años $2002(80,78 \%)$ y $2003(93,44 \%)$, es decir, tras la crisis económica que este país sufrió en 2001. La evolución del crecimiento de ciudadanos del resto de países ha sido más discreta en valores relativos, pero no en absolutos, puesto que, al igual que Argentina, ya contaban en 1998 con elevadas cantidades de población. De este grupo distinguimos, por un lado, a los marroquíes, que han crecido durante el periodo analizado en 569,0\%, siendo el año 2002 el que registró el mayor incremento anual, 56,30\%. Por otro lado, británicos, alemanes y holandeses presentan los menores incrementos relativos de extranjeros para el periodo $1998-2005$ en la provincia: $242,0 \%, 115,3 \%$ y $100,5 \%$, respectivamente; mientras que los incrementos anuales no superan en ningún caso el $40,0 \%$.

\subsection{Distribución geográfica de las principales nacionalidades}

Las principales nacionalidades extranjeras censadas en la provincia de Alicante se distribuyen mayoritariamente en los municipios del litoral, y en mucha menor medida en los del interior. Hay que distinguir entre las comarcas de la Vega Baja, al sur, y de la Marina Alta y Marina Baja al norte; donde se localizan los contingentes mayoritarios de extranjeros procedentes de los países de la UE. Además, hay otros colectivos de residentes extranjeros cuya presencia ha suscitado interés, como el caso de los noruegos (Valero, 1986), de los suizos (Huber, 2003), o de los franceses (Sempere, 1997) (Bonmatí, 1987),

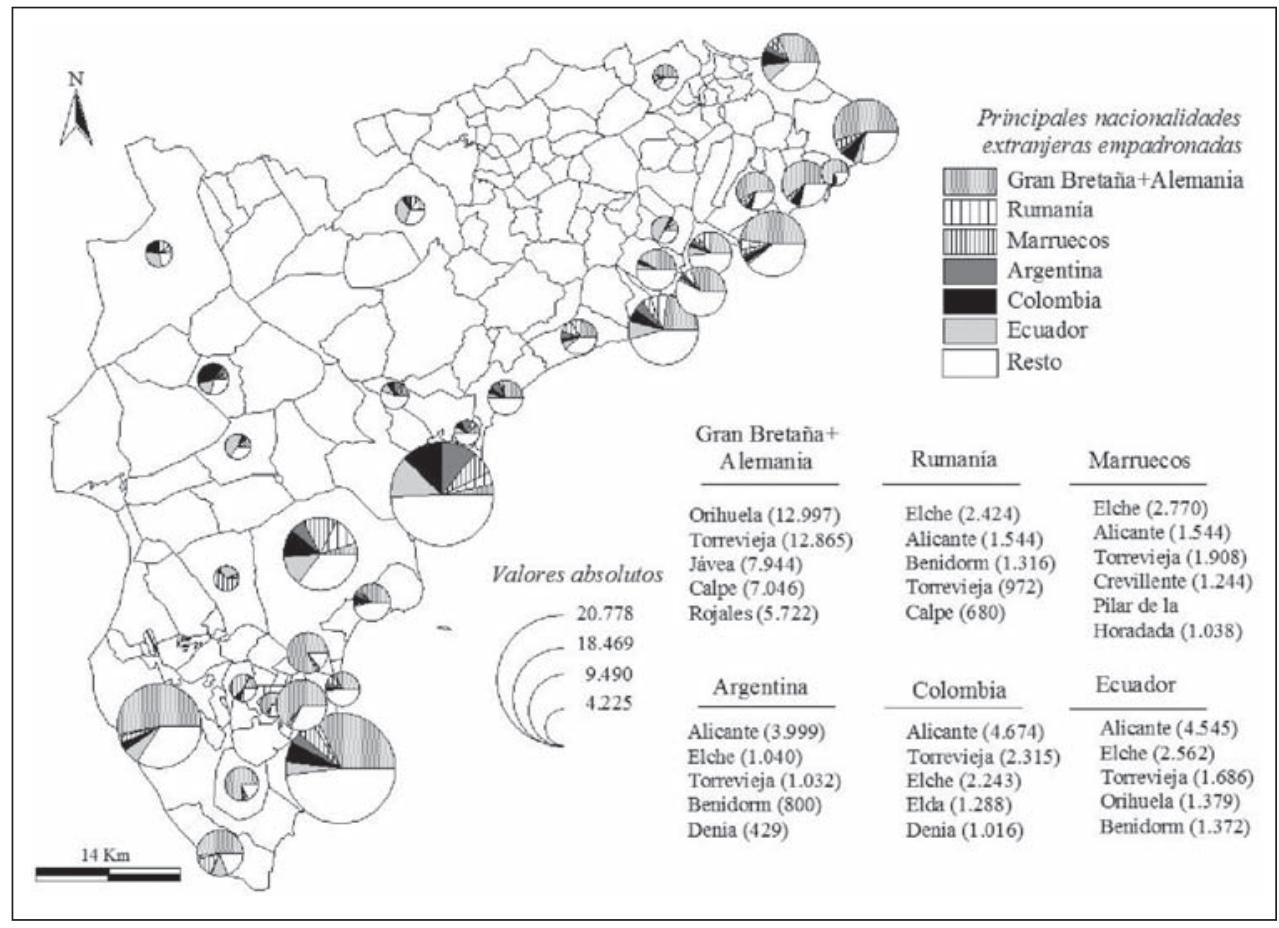

MaPA 4. Alicante 2005, principales nacionalidades empadronadas en la provincia de Alicante Fuente: INE, revisión del Padrón municipal de habitantes, a 1-01-2005. Elaboración propia. En los municipios, sólo se registran las poblaciones de más de 1.800 extranjeros totales. 
aunque estos últimos son, en buena proporción, emigrantes retornados del norte de África. En cuanto a otras nacionalidades, señalemos que se reparten de modo más homogéneo en la provincia, tanto en el litoral como en el interior, pero sobre todo en las dos grandes ciudades: Alicante y Elche.

En 2005 los británicos y alemanes son mayoritarios en Orihuela con 12.997, Torrevieja 12.865, Jávea 7.944, Calpe 7.046 y Rojales 5.722. La mayor cantidad de extranjeros latinoamericanos proceden de Ecuador, Colombia y Argentina, y residen fundamentalmente en Alicante, Elche y Torrevieja y en otros tantos municipios del litoral (mapa 4), a excepción de los colombianos en el municipio interior de Elda, que es el cuarto municipio de la provincia preferido por este colectivo nacional con 1.288 personas. Por su parte los rumanos, al igual que el grupo anterior, se encuentran representados mayoritariamente en Elche y Alicante, además de otros municipios litorales. Por último, el mayor número de marroquíes están establecidos principalmente en Elche, Alicante y Torrevieja; y también en el municipio interior de Crevillente y en Pilar de la Horadada.

\subsection{Estructura por edad y sexo de los extranjeros}

La estructura por edad y sexo de los extranjeros asentados en la provincia de Alicante presenta perfiles diferentes según la nacionalidad. Los británicos, alemanes y holandeses tienen una estructura por edades envejecida, puesto que los mayores contingentes de esta población se concentran en los grupos de 50 y más años de edad, al contar con el $30 \%$ de su población total. Los otros grupos de edades son minoritarios, si bien se aprecia un progresivo aumento de los contingentes de población desde los 0 años a los 14 años, y desde los 25 años hasta prácticamente los 64 años, lo que sin duda representa un progresivo aumento año a año de la población adulta europea y de sus hijos, tendencia que por otra parte ya ha sido observada en otras provincias españolas (Valero, 2006). Los extranjeros latinoamericanos presentan una estructura por edad y sexo más equilibrada y joven, puesto que los grupos de edad mayoritarios corresponden a los que tienen entre 25 y 40 años; además, en los grupos de edad más jóvenes se observa un notable aumento de los niños, lo que en primer lugar muestra la natalidad de las mujeres de estas nacionalidades, y en segundo lugar, la inmigración familiar y/o reagrupación familiar. Los ciudadanos marroquíes empadronados en la provincia de Alicante tienen la estructura por sexo más descompensada entre los extranjeros analizados. Aún así, se trata de una población joven ya que el grupo mayoritario es el de los 25 a 34 años, en el que por cada tres hombres hay una mujer; situación que es bastante similar en las restantes cohortes de edad, en especial las edades a partir de los 19 años. Ese desequilibrio por sexos, se explica por ser una inmigración masculina reciente que acude a trabajar principalmente en el sector agrario a la espera de reagrupar a la familia, de manera que entre los niños hay mayor equilibrio entre sexos. A su vez esta población proviene de un país en el que la mujer, además de emigrar en menor cantidad que los varones, tiene un papel socialmente menos reconocido. El desarrollo de la reagrupación familiar queda patente en el inicio de ensanche de la base de la pirámide. Por último, los rumanos presentan una estructura por edades joven, y con equilibrio entre sexos, si bien descompensada en las edades, puesto que la mayoría de esta población se concentra entre los 20 y los 34 años de edad, con más del 54\% del total de personas con esta nacionalidad; el peso de las edades más jóvenes, pero sobre todo las de más de 60 años de edad, tienen muy escasa representación, dado el carácter muy reciente de la inmigración de este colectivo y su dedicación laboral. 


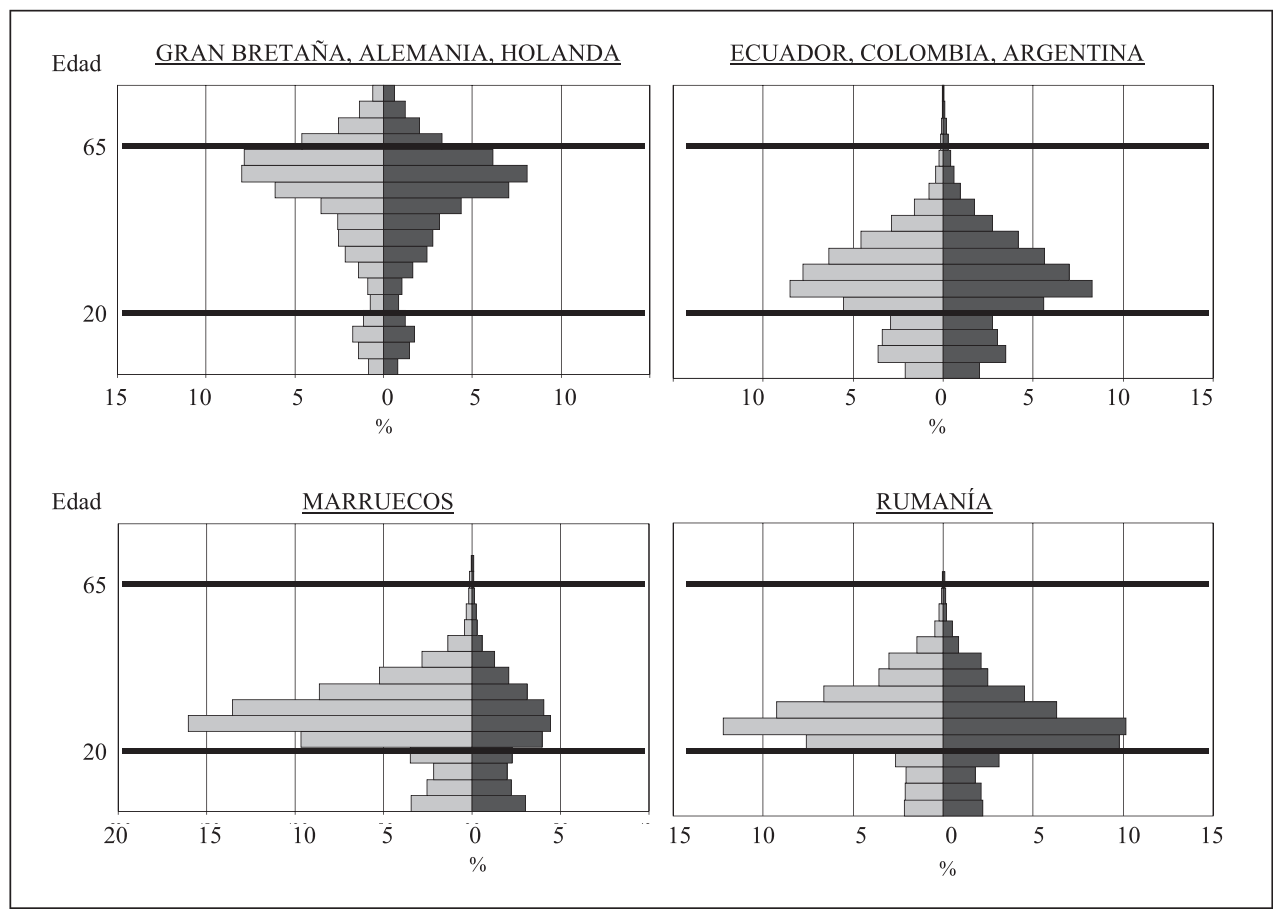

FIgura 1. Estructura por edad y sexo de las principales nacionalidades de los extranjeros en la provincia de Alicante, 2005

Fuente: INE, revisión del Padrón municipal de habitantes a 1 de enero de 2005. Elaboración propia.

\subsection{Distribución de la edad media de los extranjeros}

La edad media de los extranjeros censados en España es de 33,39 años, mientras la de los extranjeros en la provincia de Alicante es de 43,80 años. Este dato es significativo al relacionarlo con las nacionalidades europeas occidentales, muy bien representadas en la provincia. Es decir, una buena parte de los extranjeros residentes en la provincia de Alicante son turistas residenciales que están más próximos a edades potencialmente inactivas. En ese sentido la estructura por edades de la población extranjera queda reflejada atendiendo a la distribución municipal de la edad media de estas personas (mapa 5). El mapa municipal evidencia cómo los extranjeros residentes en las comarcas de la Vega Baja y Marina Alta tienen edades medias que superan el promedio provincial de los extranjeros, al contar con edades medias comprendidas entre los 43,80 y los 61,27 años. En el lado opuesto se sitúan los principales municipios de las comarcas interiores y/o industriales del Vinalopó, Alacantí, Alcoià y Comptat, cuyos extranjeros cuentan con las edades medias más jóvenes, que oscilan entre los 26,46 y los 31,15 años; si bien en estas comarcas también se encuentran algunos municipios pequeños donde la edad media de los extranjeros es un poco más elevada, lo que se relaciona con la urbanización de antiguos suelos agrícolas con fines residenciales para atraer a turistas residenciales europeos que buscan nuevos lugares para fijar su lugar de residencia en España, alejados del litoral saturado. 


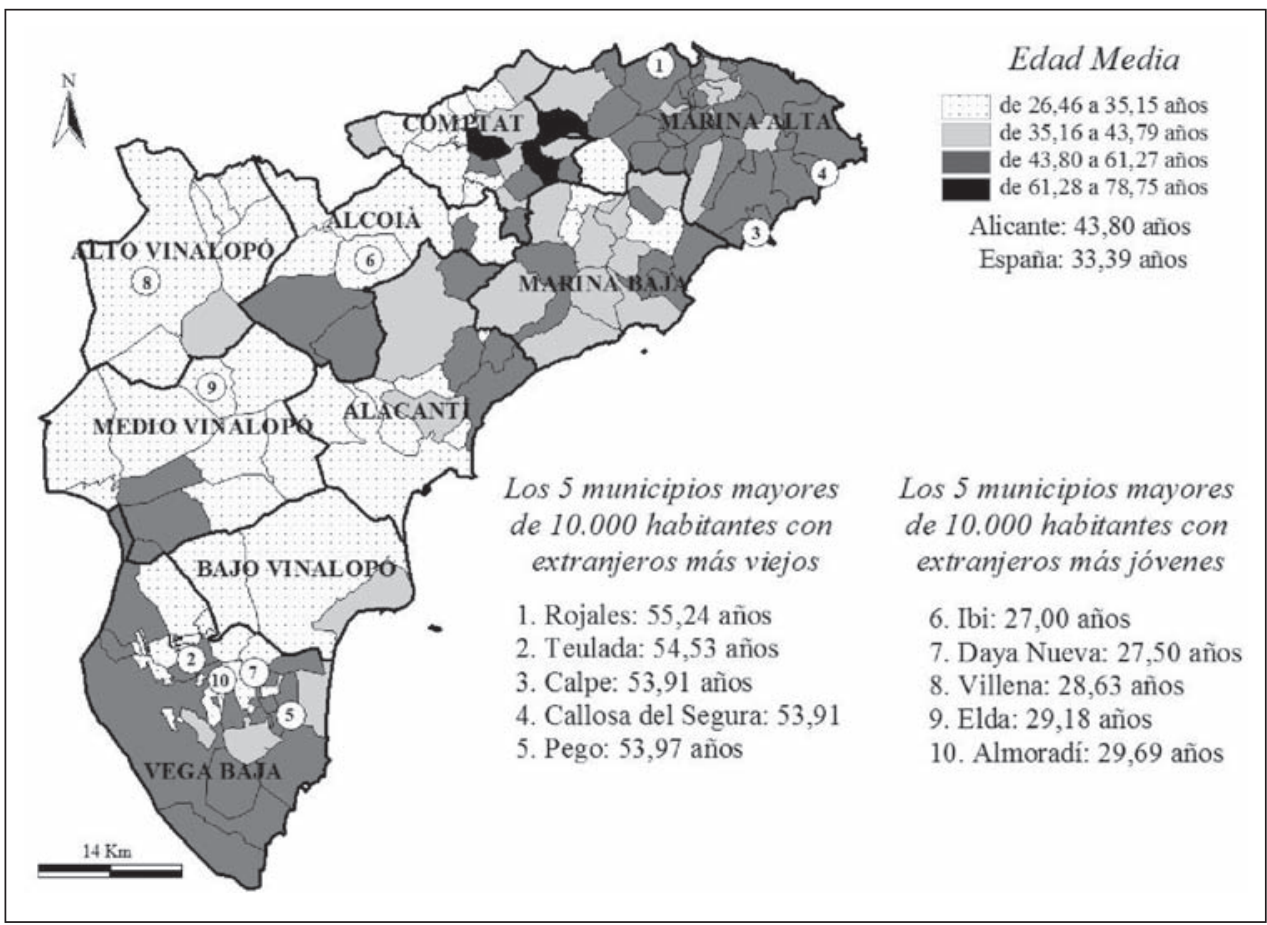

Mapa 5. Edad media de los extranjeros censados en la provincia de Alicante Fuente: INE, Censo de la población española de 2001. Elaboración propia.

Los cinco municipios mayores de 10.000 habitantes de la provincia de Alicante cuyos extranjeros tienen la edad media más elevada se sitúan en el litoral o prelitoral; pero en ningún caso se trata de los municipios demográficamente más poblados, al contar éstos con una elevada diversificación en la procedencia de sus extranjeros. Estos municipios, cuyos extranjeros tienen una edad media entre los 53,97 y los 55,24 años son: Rojales, Teulada, Calpe, Callosa de Segura y Pego, en cuyos respetivos términos municipales existen complejos residenciales concebidos especialmente para extranjeros europeos, los cuales se encuentran próximos a los mayores núcleos urbanos de sus respectivas comarcas. En cuanto a los municipios mayores de 10.000 habitantes cuyos extranjeros poseen las edades medias más bajas, entre 27,00 y 29,69 años, podemos señalar que se trata de núcleos urbanos mucho más consolidados que los anteriores, pero sobre todo con un vocación económica industrial: Ibi y Elda; o agrícola: Daya Nueva y Almoradí; o una mezcla de ambas: Villena. En cualquier caso son municipios alejados del litoral. Lo cual muestra cómo frente a un litoral con abundante cantidad de población extranjera residente de edad adulta o vieja, especialmente de la Europa económicamente más desarrollada, queda el interior provincial con menor proporción de extranjeros, los cuales proceden de países económicamente menos avanzados, que han acudido para trabajar y residir, y con edades medias jóvenes. 


\subsection{Los extranjeros y su relación con la actividad}

La distinción que se ha establecido entre la nacionalidad de los extranjeros y su distribución geográfica en la provincia de Alicante, está directamente ligada con la relación existente entre la actividad y la nacionalidad. Pese a disponer sólo de los datos de 2004, al no contar con los datos más recientes posteriores a la regularización extraordinaria de 2005, la información proporcionada por la Tesorería General de la Seguridad Social, cruzada con los datos de población ofrecidos por el INE, muestra tres aspectos fundamentales en la relación de los extranjeros con la actividad en la provincia; a) las bajas proporciones de extranjeros contratados de la Europa económicamente más desarrollada, frente a otras nacionalidades, b) las bajas proporciones de extranjeros contratados procedentes de países económicamente menos desarrollados en relación a su población potencialmente activa (entre los 16 y 65 años) y a los demandantes de empleo; es decir, hay un numeroso contingente de estos extranjeros, en edad activa, que no figuran en las estadísticas oficiales de empleo, c) hay mayor número de contratos que de personas contratadas, que es un reflejo de la enorme movilidad laboral en el colectivo de los extranjeros.

Conviene igualmente incidir sobre otros aspectos importantes, pues llama la atención la inclusión de numerosos franceses e italianos dentro de este grupo de población vinculado con la actividad, puesto que no pertenecen al colectivo de extranjeros más numerosos de la provincia. Así, hay un significativo grupo de franceses (pieds-noirs) en Alicante que desde hace varias décadas viven en la provincia y han transmitido a su descendencia esa nacionalidad. En cuanto a los italianos hay que tener presente que bajo esta nacionalidad hay población que ha nacido y vivido durante muchos años en otros países, principalmente Argentina, y que a comienzos de la presente centuria acuden a la provincia como trabajadores comunitarios con la ciudadanía italiana.

En cuanto a los extranjeros contratados en 2004 (cuadro 2), el mayor número corresponde a los marroquíes, con 10.552 (75,5\% de los que tienen entre 16 y 65 años de edad), seguidos por ecuatorianos $8.853(44,7 \%)$, colombianos $4.761(31,7 \%)$ y británicos 4.420 $(11,8 \%)$, precisamente cuatro de las cinco nacionalidades mayoritarias que residen en la provincia. Aún teniendo en cuenta las deficiencias de esta información respecto a la realidad laboral de la población, puede apreciarse una tendencia según la cual los extranjeros procedentes de países económicamente menos avanzados, en 2004 han alcanzado mayores proporciones de trabajadores contratados que los de países económicamente más avanzados: holandeses $683(11,4 \%)$, alemanes $1.879(11,2 \%)$ y británicos $4.220(11,8 \%)$ (cuadro 2). Señalemos igualmente que argelinos, 2.055 (44,8\%) e italianos, 3.946 (56,5\%), tienen mayores proporciones de persoas contratadas en 2004 que los países citados. Respecto a estos últimos, y teniendo en cuenta la existencia de los argentinos con nacionalidad italiana, llama la atención la elevada proporción de contratos registrados al ser ciudadanos de la UE, los cuales no encuentran los mismos impedimentos burocráticos y/o administrativos que los ciudadanos pertenecientes a terceros países.

Respecto a los extranjeros demandantes de empleo vuelve a repetirse la situación anterior, es decir británicos 308 ( $0,9 \%$ de los que tienen entre 16 y 65 años de edad), holandeses $105(1,8 \%)$ y alemanes $286(1,7 \%)$, presentan las menores proporciones de población que solicitó empleo en 2004; mientras que las máximas proporciones corresponden a italianos $389(9,9 \%)$, argelinos $392(8,5 \%)$ y franceses $330(7,4 \%)$, lo que muestra en el primer y tercer caso la facilidad con la que cuentan estos extranjeros de cara a la solicitud de empleo por el hecho de ser ciudadanos de la UE. En cambio, entre los colectivos más numerosos de extranjeros, ecuatorianos, colombianos, rumanos o argentinos, que poseen significativos contingentes de población «no regularizada», no entran con la misma facilidad en 
Cuadro 2

RELACIÓN DE LOS EXTRANJEROS CON LA ACTIVIDAD EN LA PROVINCIA DE ALICANTE, 2004. PRINCIPALES NACIONALIDADES

\begin{tabular}{|l|c|c|c|c|}
\hline & $\begin{array}{c}\text { Extranjeros entre } \\
\text { 16 y 65 años }\end{array}$ & $\begin{array}{c}\text { Personas } \\
\text { contratadas }\end{array}$ & $\begin{array}{c}\text { Número de contratos } \\
\text { realizados }\end{array}$ & $\begin{array}{c}\text { Demandantes } \\
\text { de empleo }\end{array}$ \\
\hline Marruecos & 13.979 & $10.552(75,5)$ & 18.363 & $949(6,8)$ \\
\hline Ecuador & 19.805 & $8.853(44,7)$ & 16.455 & $759(3,8)$ \\
\hline Colombia & 15.210 & $4.761(31,7)$ & 9.200 & $822(5,4)$ \\
\hline Reino Unido & 35.625 & $4.220(11,8)$ & 5.725 & $308(0,9)$ \\
\hline Italia & 3.946 & $2.230(56,5)$ & 4.254 & $389(9,9)$ \\
\hline Argelia & 4.589 & $2.055(44,8)$ & 4.214 & $392(8,5)$ \\
\hline Alemania & 16.705 & $1.879(11,2)$ & 2.727 & $286(1,7)$ \\
\hline Argentina & 7.603 & $1.526(20,1)$ & 2.781 & $319(4,2)$ \\
\hline Rumania & 6.866 & $1.441(21,0)$ & 2.679 & $154(2,2)$ \\
\hline Francia & 4.478 & $1.250(27,9)$ & 1.967 & $330(7,4)$ \\
\hline Rusia & 4.582 & $1.191(26,0)$ & 2.247 & $174(3,8)$ \\
\hline Holanda & 5.989 & $683(11,4)$ & 1.004 & $105(1,8)$ \\
\hline
\end{tabular}

Fuente: Tesorería General de la Seguridad Social 2006. Elaboración propia (los datos laborales y de población se refieren a todo año 2004 con fecha 1-01-2005). Excepto Rumanía y Holanda, se representan las 10 primeras nacionalidades en la demanda de empleo.

los circuitos oficiales que registran tanto a las personas que trabajan como a aquéllas que solicitan trabajo.

En cuanto al tipo de empleo de la población extranjera, nos remitimos al informe elaborado por el Observatorio Ocupacional de Alicante «Informe del colectivo de extranjeros en el mercado de trabajo de Alicante, 2004», el cual señala, como años atrás hiciera V. Gozálvez (1992), que los trabajadores de los países económicamente más avanzados de Europa desempeñan actividades de servicios en los municipios donde más compatriotas suyos residen; mientras que el resto de nacionalidades realizan los trabajos rechazados por los españoles, según la especialidad económica-productiva del lugar, así como trabajos del sector terciario como la atención domiciliaria, limpieza, hostelería, comercio, entre otros, así como en la construcción o en la agricultura.

En ese sentido el perfil de los extranjeros ocupados en la provincia de Alicante se ha mantenido durante los últimos años, puesto que el Censo de población de 2001 muestra cómo la construcción (20,1\% del total de los extranjeros ocupados), seguida por la hostelería $(15,6 \%)$, las industrias manufactureras $(13,0 \%)$, el comercio $(12,4 \%)$ y las actividades del sector primario $(10,8 \%)$, son las actividades que emplean el mayor número de extranjeros Por sexos hay más hombres ocupados 62,9\% (26.482) que mujeres 37,1\% (15.631), apreciándose la existencia de; a) actividades eminentemente masculinas: construcción, industria manufacturera y agricultura; b) actividades femeninas: servicio doméstico (cuadro 3). El resto de actividades tienen un reparto más equilibrado, si bien en el comercio y en 
Cuadro 3

PROPORCIÓN DE EXTRANJEROS OCUPADOS EN LA PROVINCIA DE ALICANTE POR ACTIVIDAD Y SEXO, 2001

\begin{tabular}{|l|c|c|c|}
\hline Actividad Económica & Total & hombres & mujeres \\
\hline \multirow{2}{*}{ Construcción } & 20,1 & 19,0 & 1,1 \\
& 8.482 & 7.994 & 488 \\
\hline \multirow{2}{*}{ Hostelería } & 15,6 & 7,5 & 8,1 \\
& 6.569 & 3.144 & 3.425 \\
\hline \multirow{2}{*}{ Industria Manufacturera } & 13,0 & 8,8 & 4,2 \\
& 5.471 & 3.717 & 1.754 \\
\hline \multirow{2}{*}{ Comercio } & 12,4 & 7,5 & 4,9 \\
& 5.232 & 3.139 & 2.093 \\
\hline \multirow{2}{*}{ Agricultura } & 10,8 & 8,9 & 1,9 \\
& 4.568 & 3.768 & 800 \\
\hline \multirow{2}{*}{ Servicios Empresariales } & 7,1 & 3,4 & 3,7 \\
& 2.979 & 1.441 & 1.538 \\
\hline \multirow{2}{*}{ Servicio doméstico } & 6,5 & 0,5 & 6,0 \\
\hline \multirow{2}{*}{ Transporte } & 2.758 & 205 & 2.553 \\
\hline \multirow{2}{*}{ Resto } & 3,3 & 2,2 & 1,1 \\
& 1.410 & 935 & 475 \\
\hline
\end{tabular}

Fuente: INE, Censo de la población de España 2001. Las actividades económicas seleccionadas corresponden a la Clasificación Nacional de la Actividad Económica a 1 dígito (CNAE93). Elaboración propia.

el transporte los hombres son mayoritarios, y en la hostelería y los servicios a empresas predominan las mujeres.

\section{La inmigración extranjera reciente en una ciudad media de tipo industrial: La conurbación Elda-Petrer}

El estudio de la inmigración extranjera en la provincia de Alicante se ha abordado tradicionalmente desde una óptica supramunicipal, si bien hay municipios emplazados en el litoral que han sido estudiados más detalladamente, y en donde se han producido grandes cambios sociales, así como territoriales, inducidos por el turismo residencial, al haber surgido en poco tiempo grandes complejos residenciales (Mazón, 2005). En el lado opuesto, los municipios del interior de la provincia parecen haber estado aislados hasta fechas muy recientes de los procesos de recepción de inmigrantes extranjeros. En ese sentido hemos identificado al municipio de Elda, cabecera de la comarca del Medio Vinalopó, como el municipio de interior que en 2005 tiene el mayor número absoluto de inmigrantes; interesa, pues, un estudio más detallado de las características y distribución 
geográfica de los extranjeros en esta ciudad. No obstante, a la hora de caracterizar a esta población, no se puede olvidar que esta ciudad forma una conurbación con Petrer; de modo que ambas ciudades, con 87.959 habitantes en 2005, constituyen el conjunto urbano más poblado del interior provincial. Además, tienen una economía eminentemente industrial, a diferencia de los municipios litorales terciarios, lo que repercute sociodemográficamente en la población y en el origen de la actual configuración y segregación urbana.

\subsection{Evolución reciente de los extranjeros y principales nacionalidades}

Entre 2001 y 2005 la población de la conurbación Elda-Petrer ha aumentado en 6.228 habitantes, al pasar de 81.731 a 87.959 personas, de los que 2.038 son extranjeros y 4.190 españoles. Sin embargo, el crecimiento relativo de la población extranjera durante este periodo es muy superior al de la población autóctona: 91,9\% frente a un $5,3 \%$. Lo que demuestra la importancia que tienen los procesos inmigratorios recientes, cuyo precedente se encuentra en la presencia de inmigrados procedentes de otras regiones españolas llegados a partir de los años 1960, quienes, entre otros aspectos sociodemográficos, contribuyeron decisivamente a la actual estructura demográfica de la población (Rosselló, 1985).

En cuanto a las doce nacionalidades con mayor presencia en la conurbación, puede apreciarse cómo los colombianos, junto con los ecuatorianos, ocupan el primer y segundo puesto, respectivamente. De la misma manera, se observa que todas las nacionalidades identificadas, a excepción de franceses e italianos, corresponden a países económicamente menos desarrollados que España. Señalemos que existe una preponderancia de ciudadanos procedentes de América Latina, ya que junto a colombianos y ecuatorianos, se encuentran significativos contingentes de argentinos, bolivianos y cubanos; el resto de las principales nacionalidades se reparten entre ucranianos y rumanos de Europa Oriental, marroquíes y argelinos de África y, por último, los chinos, que son la cuarta nacionalidad más representada tras los argentinos (cuadro 4).

En la evolución interanual de la población extranjera, en su conjunto y por nacionalidades principales, se aprecia un descenso continuado en el ritmo de crecimiento desde el año 2003, ya que se pasa de un incremento anual de $31,7 \%$ en ese año, al 19,5\% en el siguiente y al 10,0\% en 2005. Un ejemplo de ello es el descenso en cifras absolutas de colombianos -2 , y de ecuatorianos -12 , entre 2004 y 2005, si bien hay otras nacionalidades que continúan creciendo: marroquíes $48,5 \%$, italianos $24,5 \%$ y argentinos $21,2 \%$. Al mismo tiempo podemos destacar cómo otras nacionalidades que no figuran entre las más numerosas, adquieren año a año mayor relevancia; en concreto se trata de los británicos, que entre 2001 y 2005 han pasado de 10 a 53 ciudadanos, y cuya presencia en ambos municipios refleja el importante peso que este colectivo tiene en la provincia, puesto que poco a poco se adentran en espacios más alejados de la costa y que tradicionalmente no han resultado atractivos para los turistas residenciales.

\subsection{Distribución de los extranjeros en la conurbación Elda-Petrer}

La distribución de los extranjeros en los distintos barrios que componen la conurbación Elda-Petrer, guarda una fuerte relación con las distintas zonas urbanas en las que, según J. Vilagrasa (1995), se divide una ciudad de tipo medio:

- Un centro comercial y de negocios despoblado, a caballo entre el centro histórico y zonas del ensanche decimonónico. 


\begin{tabular}{|c|c|c|c|c|c|c|c|c|c|c|c|c|c|c|c|c|}
\hline & 2 & $\stackrel{8}{2}$ & શે & ㅇ & $m$ & ' & $\stackrel{\imath}{2}$ & ' & 2 & ' & $\stackrel{\sim}{2}$ & $\stackrel{\bullet}{\sim}$ & & $\stackrel{\bar{o}}{\stackrel{\sim}{-}}$ & 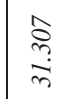 & $\begin{array}{l}\infty \\
\infty \\
i \\
\approx\end{array}$ \\
\hline 气ิ & 도 & 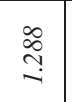 & $\vec{n}$ & $\stackrel{\infty}{2}$ & 过 & & $\bar{J}$ & ' & ळ & & $\approx$ & 아 & & $\stackrel{ \pm}{\stackrel{ \pm}{*}}$ & $\begin{array}{l}\hat{n} \\
\hat{n}\end{array}$ & $\begin{array}{l}\sqrt{n} \\
n \\
n \\
n \\
n\end{array}$ \\
\hline & 흐. & 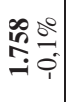 & 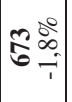 & 근 & {$\left[\begin{array}{ll}2 & 0 \\
= & 0 \\
-1\end{array}\right.$} & ' & in & . & 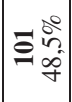 & . & 당 & 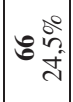 & . & 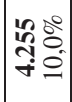 & $\frac{\overrightarrow{8}}{\infty_{\infty}^{\circ}}$ & 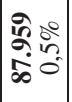 \\
\hline \multirow{3}{*}{ ఫ્ڤ } & 2 & $\stackrel{\widehat{\infty}}{\not{\sigma}}$ & I & $n$ & 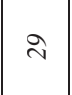 & $\approx$ & $\approx$ & $\widetilde{\sim}$ & $\cong$ & $\stackrel{n}{2}$ & $\stackrel{\infty}{-}$ & $\bar{\sim}$ & $\approx$ & $\bar{\alpha}$ & $\begin{array}{l}\stackrel{\infty}{a} \\
\grave{n}\end{array}$ & $\frac{\hat{a}}{\dot{m}}$ \\
\hline & 도 & 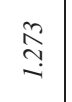 & हे & $\underset{z}{ \pm}$ & $\stackrel{\approx}{\sim}$ & $\tilde{a}$ & ळం & $n$ & $n$ & 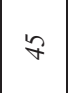 & $\infty$ & $\tilde{n}$ & $\approx$ & $\begin{array}{l}\infty \\
\infty \\
i \\
i\end{array}$ & $\begin{array}{l}\infty \\
\text { o } \\
\text { i் }\end{array}$ & 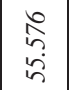 \\
\hline & $\overline{0}$ & \begin{tabular}{cc}
0 & 0 \\
0 & 0 \\
\hdashline & 0 \\
-1 & 0
\end{tabular} & $\left|\begin{array}{cc} & 0 \\
0 & 0 \\
0 & i \\
0 & n\end{array}\right|$ & 존 & 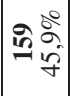 & 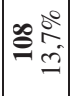 & r & $120^{\circ}$ & 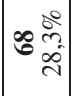 & (8) & in & 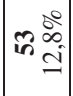 & $7 \frac{0^{\circ}}{i n}$ & $\begin{array}{ll}a & 0 \\
0 & 0 \\
\infty & 2 \\
\dot{m} & 2\end{array}$ & 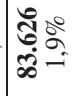 & 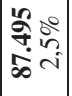 \\
\hline \multirow{3}{*}{ సิํํ } & 2 & $\underset{7}{\not}$ & ळ & $\approx$ & $\triangleq$ & 2 & $\nabla$ & $\widetilde{\sim}$ & $\approx$ & $\approx$ & $\stackrel{\sim}{\sim}$ & $\stackrel{\sim}{\sim}$ & 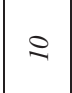 & ळొ & ָे & $\stackrel{n}{\stackrel{n}{n}}$ \\
\hline & 도 & $\stackrel{2}{\stackrel{2}{\Sigma}}$ & ఫे & $\stackrel{2}{\equiv}$ & at & $i$ & $i$ & $\bar{\gamma}$ & q & $n$ & 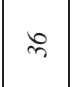 & $\widehat{\curvearrowright}$ & $\stackrel{\infty}{\sim}$ & $\underset{i}{\bar{j}}$ & $\begin{array}{l}\hat{n} \\
\hat{\sigma} \\
i\end{array}$ & 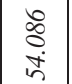 \\
\hline & $\overline{0}$ & 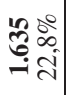 & $\begin{array}{ll}\infty & 0 \\
0 & 0 \\
n & 0 \\
\text { in }\end{array}$ & 告高 & $\begin{array}{ll}0 & 0 \\
0 & n \\
= & ?\end{array}$ & 20 $\frac{20}{2}$ & F $\frac{2}{2} \frac{0}{2}$ & 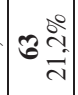 & is $\begin{array}{c}0 \\
\text { in } \\
\text { in }\end{array}$ & 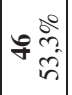 & in & 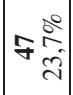 & జ & $\begin{array}{l}\hat{\tilde{n}} \\
\text { ஸ் }\end{array}$ & 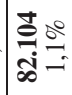 & 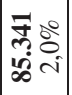 \\
\hline \multirow{3}{*}{ ิิ) } & 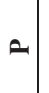 & $\frac{\nabla}{m}$ & $\hat{n}$ & $\infty$ & $?$ & $\infty$ & $n$ & $\stackrel{\imath}{\sim}$ & $\approx$ & $m$ & $\stackrel{\sim}{\sim}$ & $\infty$ & $\infty$ & $\hat{n}$ & ळे & ڤ̊ \\
\hline & 도 & 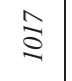 & $\stackrel{゚}{\sim}$ & $\overline{7}$ & $\stackrel{2}{2}$ & $n$ & $?$ & $i$ & $\stackrel{i}{n}$ & $\approx$ & $\infty$ & $\stackrel{\sim}{\sim}$ & $\approx$ & $\stackrel{8}{1}$ & 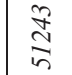 & $\frac{r}{n}$ \\
\hline & - & $\begin{array}{cc}\vec{m} & \stackrel{0}{0} \\
& \infty \\
- & \infty\end{array}$ & लि: & 15 & 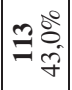 & {$\left[\begin{array}{cc}5 & 0 \\
0 & 0 \\
0 & 0\end{array}\right.$} & 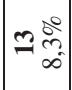 & 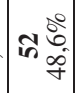 & $\begin{array}{ll}F & 0 \\
0 & 0 \\
0 & 0 \\
1\end{array}$ & लि & is & $\mid \begin{array}{ll}\infty & 0 \\
\infty & 0 \\
\infty & \infty\end{array}$ & ה。․ & 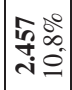 & సิㅗㅇ & 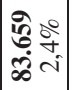 \\
\hline \multirow{4}{*}{ సิ } & 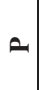 & $\widetilde{\sim}$ & $\curvearrowleft$ & $\bar{\sim}$ & $\lambda$ & $\gamma$ & $m$ & 6 & $\approx$ & $\nabla$ & $\approx$ & $\because$ & $\nabla$ & 青 & 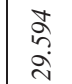 & $\stackrel{\infty}{\stackrel{\infty}{\infty}}$ \\
\hline & 조 & $\bar{\alpha}$ & 空 & 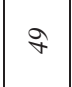 & $\mathbb{N}$ & f & $a$ & $\stackrel{\searrow}{ }$ & $\stackrel{i}{m}$ & $\bar{m}$ & r & 2 & $\infty$ & $\stackrel{\overbrace{}}{\hat{\sigma}}$ & $\begin{array}{l}\stackrel{2}{\alpha} \\
\stackrel{\alpha}{\alpha}\end{array}$ & $\frac{n}{n}$ \\
\hline & - & సี & $\frac{\theta}{m}$ & $\stackrel{R}{2}$ & $\stackrel{2}{2}$ & in & $\mathcal{I}$ & m & o & लn & हn & $m$ & $\simeq$ & $\stackrel{\bar{\lambda}}{\bar{\lambda}}$ & $\begin{array}{l}\frac{\pi}{\sqrt[n]{n}} \\
\frac{2}{2}\end{array}$ & $\stackrel{\vec{p}}{\stackrel{\infty}{\infty}}$ \\
\hline & & $\begin{array}{l}\frac{\pi}{0} \\
\frac{0}{0} \\
\frac{0}{0} \\
\end{array}$ & 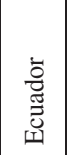 & 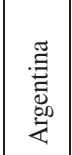 & 莺 & 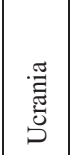 & 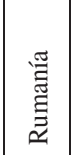 & 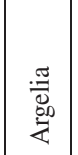 & 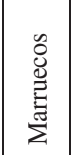 & 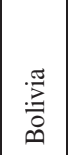 & 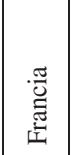 & 陉 & $\stackrel{\widetilde{0}}{\Xi}$ & 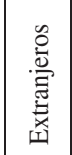 & 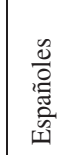 & 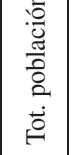 \\
\hline
\end{tabular}


- Una zona del casco antiguo en transición, con pérdidas progresivas de población, altos porcentajes de envejecimiento, síntomas de marginalidad social y regresión de la actividad económica.

- Una primera corona, que coincide con el crecimiento de ensanche, habitada por clases medias y con elevados índices de mezcla social.

- Una segunda corona, «los barrios», habitada por grupos de rentas medio-bajas o bajas.

- Un sector transversal, la «zona alta», que va desde las zonas del ensanche hasta la periferia urbana en donde vive la población con estatus social más elevado.

En relación a las rentas disponibles, los extranjeros se localizan en los emplazamientos más asequibles, es decir, en la segunda corona urbana o en enclaves de los cascos antiguos; de manera que la distribución geográfica de la población extranjera en Elda en 2004, al tener motivaciones laborales, responde en gran medida a la necesidad de encontrar un alojamiento relativamente barato.

En ese sentido los inmigrantes tienden a localizarse en los sectores urbanos consolidados que fueron levantados en décadas anteriores para absorber la inmigración laboral nacional; y que, transcurrido un tiempo, han sido progresivamente abandonados por los hijos de los antiguos inmigrantes que buscan su residencia, bien en Petrer, o, por el contrario, en los sectores urbanos del sur (sector transversal), que son los que concentran mayores crecimientos urbanos desde mediados de la década de los años noventa. De este modo distinguimos dos zonas (ambas se corresponden con la segunda corona urbana) donde la densidad de extranjeros es notable: en primer lugar destaca el barrio de la Nueva Fraternidad y sus alrededores, con relaciones entre 12,0 y $15,7 \%$ de extranjeros sobre la población total, y en segundo lugar queda una orla comprendida entre los barrios centrales de la ciudad y el cinturón periférico que engloba entre el 8,2\% y 11,9\%; en concreto se trata de los barrios de Plaza de Toros-FICIA, Cruz Roja y las proximidades a barrios como San Francisco y las Trescientas. En el resto del municipio la presencia de extranjeros es más reducida, especialmente en los sectores recientemente urbanizados, si bien hay espacios centrales de la ciudad donde en determinadas calles puede haber una presencia significativa de estos inmigrantes, cuya proporción ronda entre el $4,4 \%$ y $8,1 \%$, cifra que no es despreciable teniendo en cuenta que para el conjunto del municipio la proporción media de extranjeros es del $5,2 \%$ sobre la población total.

La población extranjera en Petrer forma parte del grupo de inmigrantes que acuden a la ciudad como fuerza laboral, dada la composición de los países de origen. A esos efectos conviene señalar que su distribución geográfica en la ciudad obedece a la disponibilidad de viviendas en función de unos recursos económicos que por lo general suelen ser inferiores al de los españoles, al tratarse de una inmigración laboral reciente. Así pues, a diferencia de Elda, los porcentajes de extranjeros en Petrer son menores; su localización más importante coincide con los barrios fronterizos con Elda, conformando con esta ciudad un sector delimitado donde la presencia de inmigrantes es notable. En concreto se trata de los sectores más orientales del Barrio de la Frontera, junto con el barrio eldense de la Nueva Fraternidad, que cuenta con porcentajes aproximados del 6,0\% de extranjeros. Otro sector de Petrer con importante presencia de extranjeros se encuentra en el Casco Antiguo y en las proximidades del Centro; en este sector de la ciudad se superan el 6,0\% de extranjeros.

\section{Conclusiones}

La provincia de Alicante es la que en 2005 tiene mayor proporción de extranjeros, pues prácticamente de cada cinco ciudadanos empadronados, uno es extranjero. Entre las nacio- 


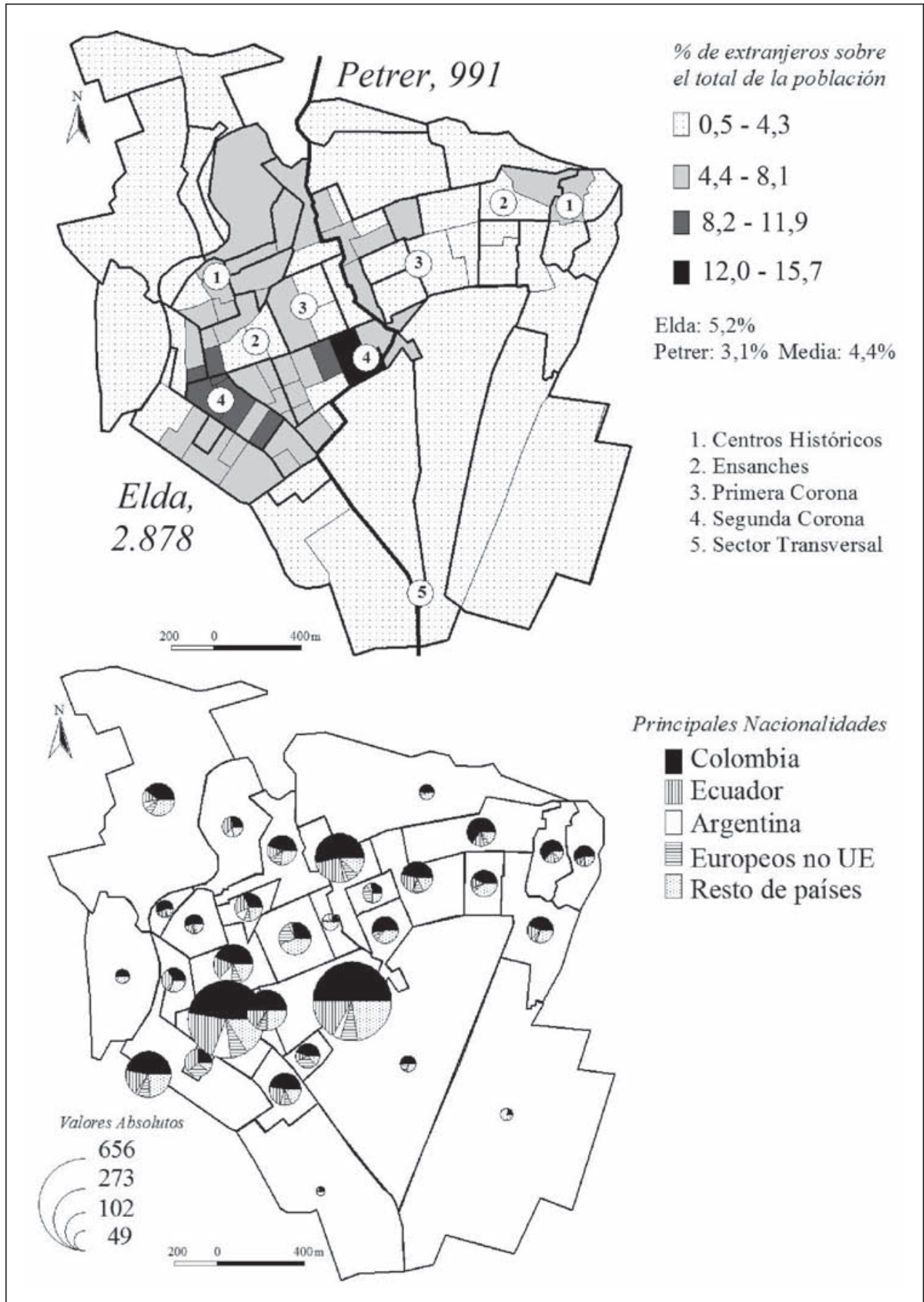

MAPA 6. Elda-Petrer 2004, distribución de la población extranjera y principales nacionalidades Fuente: INE, revisión del padrón municipal, a 1-01-2004. Elaboración propia. 
nalidades con mayor representación hay que distinguir entre los extranjeros procedentes de países europeos desarrollados: Gran Bretaña, Alemania y Holanda; y los de países menos desarrollados, de América Latina: Ecuador, Colombia y Argentina; de África: Marruecos, y de Europa del Este, Rumanía. Señalemos que el crecimiento de los extranjeros extracomunitarios ha sido más reciente e intenso que el de los europeos occidentales, quienes ya residían con elevados contingentes antes de 1998. Igualmente destaca la presencia de población con nacionalidad francesa e italiana, que en parte se corresponde con emigrantes retornados o ciudadanos de otros países, principalmente argentinos, con nacionalidad italiana.

La mayor cantidad de extranjeros se localiza en los municipios litorales, donde hay significativas proporciones de población extranjera de elevada edad media que procede de Europa Occidental, como turistas residenciales; si bien este tipo de residencialismo es más frecuente en las ciudades litorales y prelitorales que rodean a los grandes núcleos urbanos, puesto que éstos presentan una mayor diversificación de extranjeros. No obstante señalemos que en la estructura por edad de los extranjeros occidentales se aprecia un progresivo aumento en las cohortes de edad más jóvenes. En cambio, el resto de nacionalidades, que también tienen la mayor presencia en el litoral, presentan una estructura por edades más joven; y en el caso de rumanos, y sobre todo de los marroquíes, una estructura por sexo descompensada. Por su parte, en los municipios del interior de la provincia las proporciones de extranjeros son menores, concentrándose la mayor cantidad de esta población en las grandes ciudades, se trata de inmigrados que en su mayoría proceden de América Latina, Europa del Este y Magreb. Sin embargo en los pequeños municipios próximos a las cabeceras comarcales puede apreciarse la presencia de extranjeros occidentales que de manera progresiva fijan su lugar de residencia en el diseminado de estos municipios.

Por último, la distribución geográfica de los extranjeros en un núcleo urbano del interior provincial, Elda-Petrer, muestra cómo el lugar de residencia de los inmigrantes está en función de su disponibilidad económica, la cual conlleva que esta población se localice en los barrios obreros de la segunda corona urbana, en las denominadas «casas baratas» construidas durante las décadas de 1960 y 1970, cuyos antiguos residentes se han desplazado hacia el ensanche o la periferia. Además también pueden localizarse extranjeros en zonas del casco antiguo, en donde conviven grupos sociales de un estatus social medio o medio-bajo.

\section{Bibliografía}

BONMATÍ ANTÓN, J.F. (1988): La emigración alicantina a Argelia. Universidad de Alicante. Alicante, $270 \mathrm{pp}$

D`ENTREMONT, A. (1997): Geografía Económica. Cátedra, Madrid, 567 pp.

GOZÁLVEZ PÉREZ, V. (1990): «El reciente incremento de la población extranjera en España», Investigaciones Geográficas, no ${ }^{8}$, pp. 7-36

GOZÁLVEZ PÉREZ, V. (1992): «Inmigraciones recientes de extranjeros a España» en Actas de las III Jornadas de la Población Española. Málaga, pp. 9-38.

GOZÁLVEZ PÉREZ, V. (dir.) (1995): Inmigrantes marroquíes y senegaleses en la España Mediterránea. Conselleria de Treball y Afers Socials. Valencia, $442 \mathrm{pp}$.

HUBER, A. (2003): Sog des südens: altersmigrations von der Schweiz nach Spanien am Beispiel Costa Blanca. Seismo Verlag. Zürich, 295 pp.

MADERUELO, M. (2005): «La imagen de España en la inmigración europea y latinoamericana» Documentos de Trabajo (Real Instituto Elcano de Estudios Internacionales y Estratégicos), $\mathrm{n}^{\mathrm{o}} 37$. www.realinstitutoelcano.org/documentos/211/Maderuelo211.pdf

MAZÓN, T. (dir.) (2005): Turismo residencial y cambio social: nuevas perspectivas teóricas y empíricas. Caja de Ahorros del Mediterráneo. Alicante, 565 pp.

PÉREZ DÍAZ, V., ÁLVAREZ MIRANDA, B. y GONZÁLEZ ENRIQUEZ, C (2001): España ante la inmigración. Fundación la Caixa. Barcelona, 240 pp. 
ROSSELLÓ i VERGER, V.M. (1984): 55 ciutats valencianes. Universitat de València, València. $280 \mathrm{pp}$.

SEMPERE SOUVANNAVONG, J.D. (1997): Los «Pieds-Noirs» en Alicante. Las migraciones inducidas por la descolonización. Universidad de Alicante. Alicante, 123 pp.

VALERO ESCANDELL, J.R. (1992): La inmigración extranjera en Alicante. Instituto de Cultura Juan Gil-Albert. Alicante, 320 pp.

VALERO ESCANDELL, J.R. (2006): «Las inmigraciones internacionales: motor de cambios sociodemográficos y territoriales», X Congreso de la Población Española. Pamplona. (en prensa)

VILAGRASA IBARZ, J. (1995): «Segregación social urbana: introducción a un proyecto de investigación», Anales de Geografía de la Universidad Complutense, $\mathrm{n}^{\circ}$ 15, pp.817-830

VV.AA. (2004): La inmigración y el mercado de trabajo en España. Consejo Económico y Social (CES). Madrid, $170 \mathrm{pp}$.

VV.AA (2005): Informe del colectivo de extranjeros en el mercado de trabajo de Alicante, 2004. Observatorio Ocupacional de Alicante. INEM.

www2.inem.es/Observatorio/dirinte2005/ficheros/Extranjeros2004-Alicante.pdf 